life, which needs to be confirmed by testing. This applies to dried, frozen, and fresh milk. It should be labelled as unsuitable for babies under 6 months of age; and recommendations about vitamin and folic acid supplements and a nutritional analysis should be available. The free availability of a product labelled as an "All purpose whole milk powder," without qualification, is particularly dangerous.

L S TAITZ

Senior lecturer in paediatrics (supported by a grant from the CHRIS Fund)

B L ARMITAGE Senior dietitian

Children's Hospital,

Sheffield S10 2TH

1 Anonymous. Spray dried goats' milk powder. Auckland: Healtheries of New Zealand Ltd.

${ }^{2}$ Tracy JB. Infant feeding-the simple method. Bury St Edmunds: British Goat Society. (Leaflet No 43.)

${ }^{3}$ Taitz LS, Byers HD. High calorie osmolar feeding and hypertonic dehydration. Arch Dis Child 1972;47:257-60.

${ }^{4}$ Department of Health and Social Security. Present day practice in infant feeding, 1980. London: HMSO, 1981. (Reports on Health and Social Subjects, No 20.)

${ }^{5}$ Taitz LS. Solute and calorie loading in young infants: short- and longterm effects. Arch Dis Child 1978;53:697-700.

${ }^{6}$ Levine MI. A pediatrician's view: nutrition. Pediatr Ann 1981;1:7-11.

' Kirke P. Human consumption of goats' milk. Ir Med f 1979;72:492.

"Tripp JH, Francis DEM, Knight JA, Harries JT. Infant feeding practices: a cause for concern. Br Med f 1979;ii:707-9.

${ }^{9}$ Birkbeck JA. Goat milk in infant feeding. NZ Med f 1978;87:365.

10 Department of Health and Social Security. Artificial feeds for the young infant. London: HMSO, 1980. (Reports on Health and Social Subjects, No 18.)

\section{Towards a medical eugenics?}

\begin{abstract}
Almost exactly a year ago the $B M \mathcal{F}$ acknowledged the imminent arrival of the future in an editorial on the impact of the new genetics on the prenatal diagnosis of genetic disease. ${ }^{1}$ The new genetics progresses less sedately than the old, and in the months that have elapsed since then many of the questions raised in general terms in that article have assumed a more concrete and immediate form. Peter Harper has already outlined $^{2}$ some of the implications of the newly discovered genetic marker for Huntington's disease ${ }^{3}$; a very similar marker was reported at about the same time for the much commoner phenylketonuria ${ }^{4}$; and on page 431 Pope et al describe the direct detection of one of the collagen gene abnormalities responsible for osteogenesis imperfecta.

Meanwhile, with improvements in techniques for sampling fetal tissue during the first trimester of pregnancy, ${ }^{56}$ the risk associated with prenatal diagnosis has probably now dropped below the estimated $2-5 \%$ risk of a genetically defective child. ${ }^{7}$ Plainly the future has its foot in the door, and some argue that it cannot be long before screening for genetic disease has to be considered seriously as a routine part of antenatal care.
\end{abstract}

Are we, then, on the brink of eliminating from the population all the genetic diseases human flesh is heir to? We are not; and some of the most serious limitations-as well as some of the most spectacular possibilities-of current molecular genetic technology are illustrated particularly clearly by the two papers on Huntington's disease ${ }^{3}$ and osteogenesis imperfecta.

From the point of view of the new genetics the crucial difference between the two diseases is that in osteogenesis imperfecta the defective gene is known and can be directly detected, whereas in Huntington's disease the gene remains unknown and its inheritance can be detected only indirectly and not always reliably. Not that osteogenesis imperfecta is by any means perfectly understood; it embraces several distinct connective tissue diseases of varying severity, and in fact one of the interesting points to emerge from the molecular analysis by Pope and his colleagues is that at least the lethal form that they have investigated requires more than one mutant gene.

In all cases of osteogenesis imperfecta, however, there are mutations in one or other of the genes for collagen. When a genetic disease results from a defect in such an abundant protein it is now relatively simple to make a radiolabelled DNA copy of the messenger RNA specifying the protein; the DNA copy will by its chemical nature adhere to the original gene in preparations of human DNA and so can be used as a probe to detect it. Whether the probe will distinguish a mutant from a normal gene depends on the vagaries of the battery of bacterial enzymes used by new geneticists to cleave the three million or so base pairs of human DNA into gene sized and below gene sized fragments. The bacterial enzymes will cut the DNA only at certain preferred sites. If one of those sites is affected by a mutation then the mutant gene will be cleaved into fragments of a different size from those of the normal gene. From this point of view Pope and his colleagues, investigating four cases of lethal osteogenesis imperfecta, were lucky: an alpha 1(I) collagen gene in their patients proved to have a large deletion easily detected by the bacterial enzymes (which are known technically as restriction enzymes-hence the term restriction fragments for the pieces into which they cleave DNA).

Because of this relatively gross defect Pope et al can offer absolutely reliable prenatal detection of the mutant gene; but they cannot on that basis alone predict lethal osteogenesis imperfecta. In each of their four cases only one of the parents had the mutant collagen gene; no abnormality could be detected in the other parent. But the parents carrying the mutant gene were either phenotypically normal or very mildly affected, and the other parents were normal. Thus the identified mutant collagen gene must be interacting with another, unknown gene (Pope et al guess that it is another collagen gene) to produce the lethal disease. Since they are unable to identify the second gene half of those fetuses diagnosed on the basis of the known mutant alone will presumably be normal. Conversely, half of those normal fetuses not carrying the known mutation will presumably be carriers for the unknown one.

All of this is in stark contrast to Huntington's disease, in which there is no such thing as symptomless carrier state and anyone carrying the gene will sooner or later develop the disease. Because the gene is unknown, however, even with the new marker it will be impossible to identify all individuals carrying it. Peter Harper has already discussed the distinctive problems posed by the late onset and ghastly prognosis of the disease; but it is worth spelling out what, in those special circumstances, can and cannot be expected of a genetic marker.

The marker for Huntington's disease is simply a piece of anonymous DNA (named G8) that happens to lie close enough to the Huntington's disease gene to be reliably inherited with it. The value of the G8 fragment as a genetic marker lies in its containing variations (polymorphisms) that are detectable by bacterial restriction enzymes and thus result in its being cleaved into fragments of different lengths in different people. Gusella et al, who discovered the marker, identified four variants (haplotypes) which they designated 
$A, B, C$, and $D .^{3}$ In the two families they investigated the disease has turned out to be inherited with different G8 haplotypes; in a large Venezuelan family it is associated with the A haplotype, and in a North American family with the $\mathrm{C}$ haplotype. Thus clearly at best diagnosis will be possible only if enough genetic and medical data can be collected from the family of any given individual patient to establish a linkage; no G8 haplotype is exclusively associated with Huntington's chorea. Indeed, all of the G8 haplotypes are present in varying proportions in the normal population, and this severely limits their usefulness even when data on the family are available. The $\mathrm{C}$ haplotype, for example, is present in about $70 \%$ of normal people, so that a hypothetical young woman at risk in the North American family may easily have either an affected father homozygous for the $C$ haplotype but not for Huntington's chorea, or both parents heterozygous for the $\mathrm{C}$ haplotype; and she will have no way of knowing, in either case, whether the $C$ haplotype she has inherited is associated with the Huntington's mutation - until she develops the signs of the disease, which is unlikely to be before she is 35 . Or again, suppose her father were heterozygous and her mother did not carry the $C$ haplotype, then the $C$ haplotype she carries must predict the disease. But if she then marries a man homozygous for the $\mathrm{C}$ haplotype she forfeits the option of prenatal diagnosis for her children.

Moreover, the young woman I have imagined is a brave and enlightened girl in no way typical of people in her position, most of whom, if various surveys ${ }^{2}{ }^{8}$ are to be believed, would rather remain in ignorance about themselves and their unborn children (it must be asking a lot of anyone to understand and accept such an option). This is a pity because the mutation responsible for Huntington's disease seems to be quite extraordinarily rare. Given the absence of a normal carrier state, and given that with time more and better markers will be identified, elective abortion of all affected fetuses in known families could virtually eliminate this singularly unpleasant disease in a very short time. ${ }^{8}$

This is an option that is seldom open in genetic disease, of which phenylketonuria is a more usual example. As a recessive disease, it has a normal carrier state and moreover probably quite frequently arises from new mutations. The existence of the carrier state complicates estimates of how frequent such mutations are, but Woo et al, reporting a genetic marker for phenylketonuria in Nature, give a figure of two in 100 for the carrier state, which suggests that they are far from rare. ${ }^{4}$ Given that most parents would refuse abortion in the case of a normal fetus carrying a single copy of the mutant gene (and which would grow up to be a healthy carrier), the prospect of eliminating phenylketonuria thus becomes extremely remote. Furthermore, the restriction enzymes have been less kind to Woo and his colleagues than they were to Pope et al: although Woo et al had a DNA probe for the phenylalanine hydroxylase gene implicated in the disease, the enzymes failed to distinguish the mutant from the normal gene and they were forced to resort to a linked marker of the sort Gusella et al identified for Huntington's disease. This means that for the time being prenatal diagnosis of phenylketonuria remains practicable only for families in which one affected child has already been born and the associated marker haplotypes can be identified by investigation of parents and affected offspring. Woo et al reckon that their marker probe should make it possible to offer prenatal diagnosis to about three quarters of such families.

So much for the present limitations of the available probes.
There is very little doubt that they will all be overcome in the near future. When, as in the case of phenylketonuria, the defective gene is known it cannot be long before the mutation has been identified, and there are now techniques for detecting single nucleotide mutations in samples of human DNA. This has already been achieved for sickle cell anaemia and one of the many forms of beta thalassaemia ${ }^{910}$; the trick is to make a short synthetic stretch of radiolabelled DNA (19 nucleotides will do) representing the part of the gene containing the mutation. These small synthetic probes will adhere much more strongly to the perfectly matching mutant DNA than they will to the imperfectly matching normal gene; these thus make possible the direct detection even of the subtlest genetic defects without the limitations imposed by the arbitrary behaviour of restriction enzymes.

In disease such as Huntington's disease and the hereditary muscular dystrophies, where the mutant gene is unknown, progress will inevitably be slower. The identification of a linked marker must eventually make possible the identification of the unknown gene itself-but it will not be easy in the absence of any clue about what to look for. On the other hand, the potential rewards are concomitantly great: Huntington's disease, for example, is caused by the programmed degeneration of a specific class of nerve cells in a way that parodies the programmed cell death that is an important part of the normal development of the embryonic nervous system. The identification of the gene responsible for Huntington's disease may help to answer fundamental questions about neural development and even cast some light on non-hereditary degenerative diseases such as parkinsonism and amyotrophic lateral sclerosis which are also curiously selective for specific subsets of neurones. I would, however, dissent from the recent editorial in the Lancet, which concluded euphorically that once the gene has been identified "therapy may be only a step away." Many of the haemoglobinopathies are understood down to the last nucleotide and remain essentially incurable. The steps to gene therapy are not one but many. The future is not as close as all that.

Miranda Robertson

Staff Editor,

Nature,

London WC2R 3LF

1 Smith T. How will the new genetics work ? Br Med f 1983;286:1-2.

2 Harper PS. A genetic marker for Huntington's chorea. $\mathrm{Br}$ Med $\mathcal{F}$ 1983; 287 :1567-8.

${ }^{3}$ Gusella JF, Wexler NS, Conneally PM, et al. A polymorphic DNA marker genetically linked to Huntington's disease. Nature 1983;306: 234-8.

4 Woo SLC, Lidsky AS, Güttler F, Chandra T, Roboon KJH. Cloned human phenylalanine hydroxylase gene allows prenatal diagnosis and carrier detection of classical phenylketonuria. Nature 1983;306:151-5.

5 Elles RG, Williamson R, Niazi M, Coleman DV, Horwell D. Absence of maternal contamination of chorionic villi used for fetal-gene analysis. $N$ Engl f Med 1983;308:1433-5.

${ }^{6}$ Rodeck CH, Morsman JM, Nicolaides KH, McKenzie C, Gosden CM, Gosden JR. A single-operator technique for first-trimester chorion biopsy. Lancet 1983;ii:1340-1.

${ }^{7}$ Weatherall DJ. The new genetics and clinical practice. London: Nuffield Provincial Hospitals Trust, 1982.

${ }^{8}$ Myers RH, Martin JB. Huntington's disease. Seminars in Neurology 1982; 2:365-72.

${ }^{9}$ Connor BJ, Reyes AA, Morin C, Itakura K, Teplits RL, Wallace RB. Detection of sickle cell beta $\mathrm{S}$-globin allele by hybridization with synthetic oligonucleotides. Proc Natl Acad Sci USA 1983;80:278-82.

${ }^{10}$ Pirastu M, Kan YW, Cao A, Conner BJ, Teplitz RL, Wallace RB. Prenatal diagnosis of $\beta$-thalassemia. Detection of a single nucleotide mutation in DNA. N Engl f Med 1983;309:284-7.

11 Anonymous. Recombinant DNA and genetic disease-answers and questions. Lancet 1983;ii:1404-5. 